\title{
Climate change is already making us sick
}

\author{
Cite as: CMAJ 2017 November 20;189:E1428-9. doi: 10.1503/cmaj.109-5527
}

Posted on cmajnews.com on Nov. 2, 2017.

limate change is already harming millions of people around the world, and urgent action is needed to reduce carbon emissions and avoid global health catastrophe, according to a new report by experts from 26 organizations, including the World Bank and the World Health Organization.

The Lancet Countdown on Health and Climate Change report warns that "the symptoms of climate change have been clear for a number of years, with the health impacts far worse than previously understood." These include increasing illness, injury and death from more frequent and intense heat, storms, floods, drought and wildfires, as well as the health fallout from crop damage and food insecurity, air pollution, water contamination, mass displacement and migration, and changing patterns of infectious diseases from animals and insects.

The diagnosis is grim, the symptoms are worsening and no one is immune, says Dr. Courtney Howard, lead author of an accompanying Canadian policy brief. Global temperatures are set to rise up to 4.8 degrees Celsius by the end of the century, a level which would be disastrous beyond our ability to adapt. "This is about our survival, flat out, our survival to 2100 and beyond," Howard says.

Heatwaves pose one of the most immediate risks. Between 2000 and 2016, the number of medically vulnerable people exposed to excessive heat increased by about 125 million. In Canada, an extreme heat event in 2009 contributed to an additional 156 deaths in British Columbia, while another in 2010 contributed to 280 more deaths in Quebec. It's estimated that heatwaves will affect a billion more people a year by 2040 .

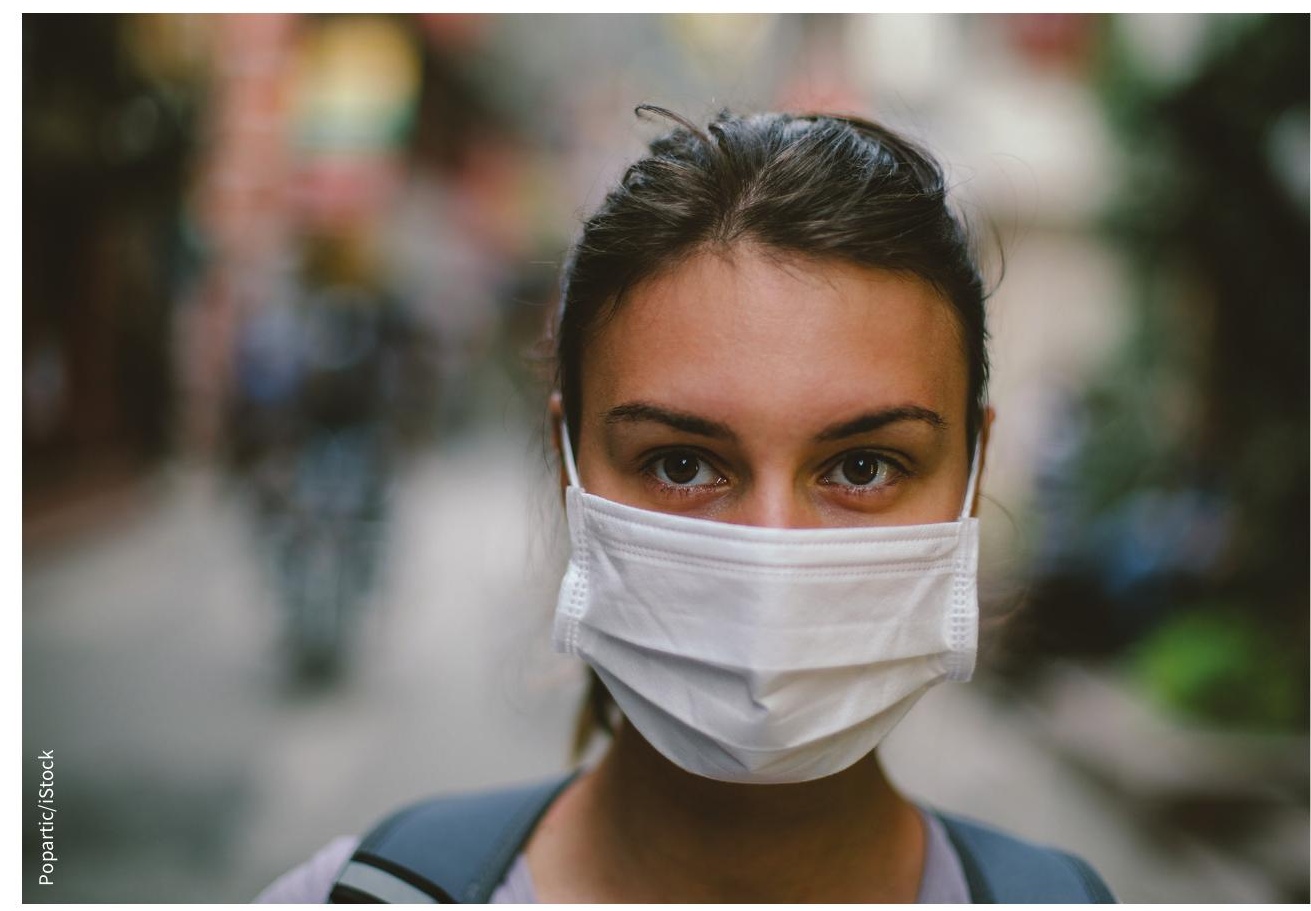

A new report finds global inaction on climate change is already jeopardizing the lives of millions, including Canadians.

Weather-related disasters have also been on the rise in Canada. Floods in Alberta in 2013 and Manitoba in 2014 affected more than 100000 people. Meanwhile, "we've seen intense wildfire seasons in the past couple of years," Howard says. Wildfires cloaked the Northwest Territories in smoke for much of the summer of 2013, forced the largest evacuation in Saskatchewan's history in 2015, and devastated Fort McMurray, Alberta, in 2016, uprooting some 88000 people.

Globally, there's been a $46 \%$ increase in weather-related disasters since 2000, causing US\$129 billion in economic losses in 2016 alone. The damage in the Caribbean from recent hurricanes will be a "point of moderate dysfunction for years," Howard says. With each blow, "you have less ability to cope with future impacts."
Beyond natural disasters, warmer temperatures are making it harder to grow food, and are expanding the range of disease-bearing insects, she says. Annual cases of dengue fever have doubled every decade since 1990, and closer to home, "Lyme disease is marching across Canada."

Food supply issues and the risk of disease transmission will only compound as rising sea levels force the mass migration of more than one billion people in the next 90 years, Howard adds.

She likens the problem to multi-organ system failure, where one organ shutting down increases the strain on others until the whole body shuts down. The good news is that there is still time to prevent that chain reaction, Howard says. "We're getting to the point now where some of 
the plans we're proposing are adequate to meet the challenge."

The Canadian policy brief accompanying the Lancet report calls for a complete phase out of coal power by 2030 or sooner, with at least two-thirds of that power being replaced by green energy sources. "Coal is responsible for $44 \%$ of global $\mathrm{CO} 2$ emissions; it's old technology and it's crappy for health in terms of pollution," says Howard. Ontario's phase-out in 2014 is estimated to have prevented 400 premature deaths and 2450 hospitalizations per year.

The brief also calls for the creation of a national active transportation strategy and strong health-sector support for Health Canada's draft healthy eating guideline, which encourages a shift to low-meat, plant-rich diet. "It's not like we all have to stop eating meat completely," says Howard. Simply reducing the amount of meat in our diet can cut emissions, land use and water use by $20-30 \%$.

Physicians and the health system also have an important role to play in combatting climate change. "The emissions of health care itself are actually quite considerable," notes Howard. "We waste a lot of materials, burn a lot of things and our lights are on all day."

The United Kingdom's National Health System has been monitoring and cutting its emissions since 1992 with a goal of achieving a $34 \%$ reduction by 2020 . The brief urges Canada to conduct similar measurements and enhance support for tele- health. "We spend a lot of money flying people around to go to the doctor and we probably don't need to," Howard explains.

The brief further recommends that public health units work together to prepare for extreme weather and natural disasters. It also urges the federal government to investigate concerns about fracking and consider health impacts as part of environmental assessments.

Physicians can help by reframing climate change as a health emergency, Howard says. "We know enough now as doctors to realize if we don't do that, it will be an abdication of our responsibility to our patients now and in the future."

Lauren Vogel, CMAJ 